\title{
Point-of-Care Estimated Radiation Exposure and Imaging Guidelines Can Reduce Pediatric Radiation Burden
}

\author{
Christopher W. Bunt, MD, Harry B. Burke, MD, PhD, Alexander J. Towbin, MD, \\ Albert Hoang, PhD, DSc, Mark B. Stephens MD, MS, Paul Fontelo, MD, MPH, \\ Fang Liu, MS, and Ronald W. Gimbel, PhD
}

Introduction: The steady increase in the use of computed tomography (CT) has particular concerns for children. Family physicians must often select pediatric imaging without any decision support. We hypothesized that point-of-care decision support would lead to the selection of imaging that lowered radiation exposure and improved guideline congruence.

Methods: Our double-blind, randomized simulation included family physicians in the Military Health System. Participants initially reviewed a pediatric hematuria scenario and selected imaging without decision support. Participants were subsequently randomized to either receive imaging-appropriateness guidelines and then estimated radiation exposure information or receive estimated radiation information then guidelines; imaging selections were required after each step. The primary outcome was the selected imaging modality with point-of-care decision support.

Results: The first arm increased CT ordering after viewing the guidelines $(P=.008)$ but then decreased it after reviewing radiation exposure information $(P=.007)$. In the second arm radiation information decreased CT and plain film use $(P=$ not significant $)$, with a subsequent increase in ultrasound and CT after the guideline presentation $(P=.05)$.

Conclusions: Decision support during a simulated pediatric scenario helped family physicians select imaging that lowered radiation exposure and was aligned with current guidelines, especially when presented with radiation information after guideline review. This information could help inform electronic medical record design.(J Am Board Fam Med 2015;28:343-350.)

Keywords: Clinical Decision Support Systems, Decision Making, Evidence-Based Medicine, Radiation, Radiology

The increased use of computed tomography (CT) may unnecessarily expose children to ionizing radiation. ${ }^{1}$ Risks associated with radiation exposure are greater in children because of their longer life span and greater radiosensitivity. ${ }^{2}$ Given the need

This article was externally peer reviewed.

Submitted 1 September 2014; revised 1 December 2014; accepted 9 December 2014.

From the Departments of Family Medicine (CWB, MBS) and Medicine (HBB, AH), Uniformed Services University, Bethesda, MD; the Department of Pediatric Radiology, Cincinnati Children's Hospital Medical Center, Cincinnati, OH (AJT); the Lister Hill National Center for Biomedical Communications, National Library of Medicine, Bethesda, MD $(\mathrm{PF}, \mathrm{FL})$; and the Department of Public Health Sciences, Clemson University, Clemson, SC (RWG).

Funding: Intramural funding was provided by the Uniformed Services University (grant no. R02930.4) and the US Department of Defense Patient Safety Program. to weigh risks and benefits before any medical test, ${ }^{3}$ physicians need to better understand doses of radiation associated with common imaging modalities. ${ }^{4}$ In current practice up to $40 \%$ of CT scans ordered are unnecessary. ${ }^{5,6}$ As a result, imaging guidelines ${ }^{7}$ and clinical decision support systems ${ }^{5}$ have been developed to improve appropriate use of medical imaging. To date, these initiatives have been inconsistently adopted and are largely unavailable for

Conflict of interest: none declared.

Disclaimer: The views expressed herein are solely the views of the authors and do not represent those of the Uniformed Services University, the United States Air Force, the United States Navy, or the Department of Defense.

Corresponding author: Christopher W. Bunt, MD, Department of Family Medicine, Uniformed Services University, 4301 Jones Bridge Rd, Bethesda, MD 20814 (E-mail: christopher.bunt@usuhs.edu). 
Figure 1. Participant study flow. After informed consent, review of a clinical case study, and an initial imaging decision, participants were randomized to 1 of 2 arms: ACR-RADS, a decision support screen presented with American College of Radiology (ACR) appropriateness criteria (ACR criteria) for each potential imaging order, followed by an imaging decision and then additional decision support with estimated radiation exposure for each potential image order (radiation exposure info) and a final imaging decision; and RADS-ACR, which presented estimated radiation exposure information followed by ACR Criteria with subsequent imaging decisions.

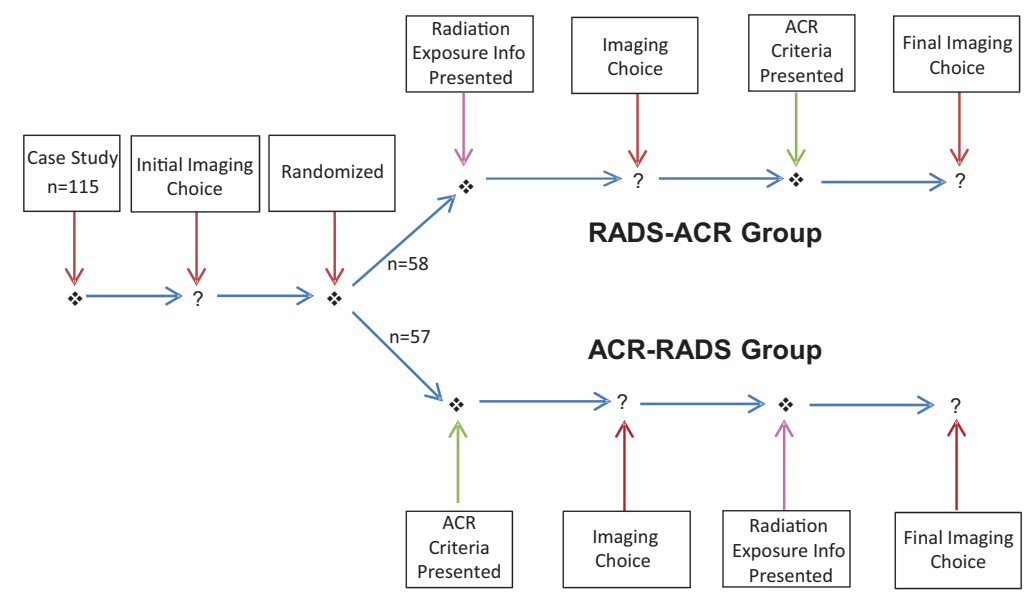

children. ${ }^{8}$ Of those available, the American College of Radiology (ACR) Appropriateness Criteria are evidence-based imaging guidelines that address imaging recommendations for different clinical scenarios, including several that involve pediatric patients. To our knowledge, no decision support products to encourage appropriate medical imaging within the clinical workflow are currently in use.

Building on our previous research, ${ }^{9}$ this study examined how decision support, in the form of estimated radiation exposure coupled with current imaging guidelines, influenced family physician selection of pediatric imaging modalities. We hypothesized that decision support information, and the order in which data were presented, would impact physician choice of imaging modality. This would ideally enhance the use of guideline-recommended imaging and lower estimated radiation exposure in pediatric patients.

\section{Methods}

A double-blind, randomized simulation trial was conducted within the 17 family medicine training programs in the Military Health System (MHS). Physicians accessed an online clinical scenario describing a 6-year-old girl with painful, nontraumatic hematuria. There was no incentive for participation and no penalty for abstaining (see the screenshots in Appendix 1).
Without the aid of clinical decision support, participants selected a single, best-choice medical imaging modality from 7 randomized options derived from the ACR Appropriateness Criteria for painful, nontraumatic pediatric hematuria. ${ }^{10}$ The 2 imaging choices rated as "usually appropriate" (the highest possible ACR category, inclusive of numeric ratings of 7 to 9) in the selected ACR Appropriateness Criteria were CT of the abdomen and pelvis without contrast (rating of 8) and ultrasound of the kidneys and bladder (rating of 7). Of these 2 modalities, the estimated pediatric radiation dose for an abdominal and pelvic CT is 3 to 10 $\mathrm{mSv}$, whereas ultrasound causes no radiation exposure.

After initial imaging selection, the study's first group was presented with the ACR Appropriateness Criteria ratings and then estimated radiation exposure information (RADS) for each imaging modality (ACR-RADS group). Participants were asked to select an imaging modality after each decision support screen. The second group had similar steps, but was presented with the same information in reverse order (RADS-ACR group; Figure 1).

Data were entered into Microsoft Excel (Microsoft Corp., Redmond, WA) and imported into SAS (SAS Institute, Inc., Cary, NC). The StuartMaxwell test was used to test for equality of distri- 
Table 1. Physician Medical Imaging Order Choices

\begin{tabular}{|c|c|c|c|c|c|c|}
\hline Order, By Group & $\begin{array}{l}\text { Initial } \\
\text { Choice }\end{array}$ & $\begin{array}{l}\text { After ACR } \\
\text { Guideline } \\
\text { Information }\end{array}$ & $\begin{array}{c}\text { Change from } \\
\text { Initial to } \\
\text { ACR }\end{array}$ & $\begin{array}{l}\text { After Radiation } \\
\text { (RADS) } \\
\text { Information }\end{array}$ & $\begin{array}{l}\text { Change from } \\
\text { ACR to RADS }\end{array}$ & Never Changed* \\
\hline \multicolumn{7}{|l|}{ ACR-RADS Group $(\mathrm{n}=57)$} \\
\hline Ultrasound & $44(77.2 \%)$ & $37(64.9 \%)$ & -7 & $46(80.7 \%)$ & +9 & $32(72.7 \%)$ \\
\hline CT, without contrast & $4(7.0 \%)$ & $18(31.6 \%)$ & +14 & $7(12.2 \%)$ & -11 & $4(100 \%)$ \\
\hline \multicolumn{7}{|l|}{ Radiography } \\
\hline Abdomen and pelvis & $8(14.0 \%)$ & $2(3.5 \%)$ & -6 & $2(3.5 \%)$ & 0 & $2(25.0 \%)$ \\
\hline $\begin{array}{l}\text { Voiding } \\
\text { cystourethrography }\end{array}$ & $1(1.8 \%)$ & 0 & -1 & 0 & 0 & 0 \\
\hline Intravenous urography & 0 & 0 & 0 & $1(1.8 \%)$ & +1 & 0 \\
\hline $\begin{array}{l}\text { MRI, with or without } \\
\text { contrast }\end{array}$ & 0 & 0 & 0 & $1(1.8 \%)$ & +1 & 0 \\
\hline \multirow{3}{*}{$\begin{array}{l}\text { Arteriography of the } \\
\text { kidneys }\end{array}$} & 0 & 0 & 0 & 0 & 0 & 0 \\
\hline & & \multicolumn{2}{|c|}{ Initial vs. guideline: $P=.008$} & \multicolumn{3}{|c|}{ Guideline vs. radiation: $P=.007$} \\
\hline & $\begin{array}{l}\text { Initial } \\
\text { Choice }\end{array}$ & $\begin{array}{l}\text { After Radiation } \\
\text { (RADS) } \\
\text { Information }\end{array}$ & $\begin{array}{c}\text { Change from } \\
\text { Initial to } \\
\text { RADS }\end{array}$ & $\begin{array}{l}\text { After ACR } \\
\text { Guideline } \\
\text { Information }\end{array}$ & $\begin{array}{l}\text { Change from } \\
\text { RADS to ACR }\end{array}$ & Never Changed* \\
\hline \multicolumn{7}{|l|}{ RADS-ACR Group $(\mathrm{n}=58)$} \\
\hline Ultrasound & $36(62.0 \%)$ & $41(70.7 \%)$ & +5 & $42(72.4 \%)$ & +1 & $31(86.1 \%)$ \\
\hline CT (without contrast) & $10(17.2 \%)$ & $4(6.9 \%)$ & -6 & $10(17.2 \%)$ & +6 & $4(40.0 \%)$ \\
\hline \multicolumn{7}{|l|}{ Radiography } \\
\hline Abdomen and pelvis & $11(19.0 \%)$ & $8(13.8 \%)$ & -3 & $6(10.4 \%)$ & -2 & $2(18.2 \%)$ \\
\hline $\begin{array}{l}\text { Voiding } \\
\text { cystourethrography }\end{array}$ & 0 & 0 & 0 & 0 & 0 & 0 \\
\hline Intravenous urography & $1(1.8 \%)$ & $2(3.4 \%)$ & +1 & 0 & -2 & 0 \\
\hline $\begin{array}{l}\text { MRI, with or without } \\
\text { contrast }\end{array}$ & 0 & $3(5.2 \%)$ & +3 & 0 & -3 & 0 \\
\hline \multirow[t]{2}{*}{ Arteriography kidneys } & 0 & 0 & 0 & 0 & 0 & 0 \\
\hline & & \multicolumn{2}{|c|}{ Initial vs radiation: $P=\mathrm{NS}$} & \multicolumn{2}{|c|}{ Radiation vs guideline: $P=.05$} & \\
\hline
\end{tabular}

*The participant never changed the imaging order.

ACR-RADS, American College of Radiology Appropriateness Criteria then estimated radiation exposure information; CT, computed tomography; MRI, magnetic resonance imaging; NS, not significant; RADS-ACR, estimated radiation exposure information then American College of Radiology Appropriateness Criteria.

butions under the initial, ACR, and RADS conditions. A power analysis and parametric comparisons between the ACR-RADS group and the RADSACR group were conducted using the $\chi^{2}$ test of homogeneity, with a $5 \%$, 2-sided significance level. A sample size of 50 per group, with a difference in proportions between groups of at least $30 \%$, led to a power exceeding $80 \%$.

\section{Results}

A total of 115 physicians were enrolled and randomized to either the ACR-RADS $(\mathrm{n}=57)$ or RADS-ACR groups $(\mathrm{n}=58)$. Most respondents were men $(75 \%)$, active military $(85 \%)$, attending physicians $(80 \%)$ from 31 to 50 years old $(70 \%)$.
There were no significant demographic differences between groups (Appendix 2).

Ultrasound was the initial imaging modality of choice for $70 \%(\mathrm{n}=80)$ of all respondents, followed by plain film $(17 \%, \mathrm{n}=19)$ and CT $(12 \%$, $\mathrm{n}=14$ ). Over half of all participants initially selected and then maintained ultrasound as their imaging choice throughout the study $(73 \%, \mathrm{n}=32$ in the ACR-RADS group; $86 \%, \mathrm{n}=31$ in the RADSACR group) (Table 1).

After presentation of the ACR Appropriateness Criteria, ultrasound selection $(77 \%[\mathrm{n}=44]$ to $65 \%[\mathrm{n}=37])$ and plain film use $(14 \%[\mathrm{n}=8]$ to $3.5 \%[\mathrm{n}=2])$ slightly decreased in the ACR-RADS group, whereas CT use $(7 \%[\mathrm{n}=4]$ to $32 \%[\mathrm{n}=$ 
18]) increased $(\mathrm{P}=.008)$. After the ACR-RADS group was subsequently presented with RADS information, ultrasound use increased $(81 \%, \mathrm{n}=46)$, whereas CT orders decreased $(12 \%, \mathrm{n}=7 ; P=$ .007) (Table 1).

In the RADS-ACR group, ultrasound use (62\% [n $=36]$ to $71 \%[\mathrm{n}=41])$ slightly increased, whereas CT use $(17 \%[\mathrm{n}=10]$ to $7 \%[\mathrm{n}=4])$ and plain film use $(14 \%, \mathrm{n}=8)$ slightly decreased; other tests $(2 \%[\mathrm{n}=1]$ to $9 \%[\mathrm{n}=5])$ increased slightly after receiving RADS information $(P=$ not significant). When this group was presented with ACR guideline information, ultrasound use slightly increased $(72 \%, \mathrm{n}=42)$, CT use $(17 \%, \mathrm{n}=10)$ returned to the level it was before decision support, and plain film use slightly decreased $(10 \%, \mathrm{n}=6$; $P=.05)$ (Table 1).

\section{Discussion}

Childhood exposure to ionizing radiation increases the lifetime risk of malignancy. ${ }^{2,8}$ To mitigate pediatric exposure, an international campaign to raise awareness about appropriate medical imaging is underway. ${ }^{11}$ Our study evaluated whether electronic medical record decision support with ACR guideline ratings and estimated RADS would change family physician decision making at the point of care.

We acknowledge that painful, nontraumatic pediatric hematuria is less common in the primary care setting. To determine whether physicians considered radiation exposure in their imaging selections, however, our construct required a pediatric scenario that had at least 2 guideline-recommended imaging choices that were at different ends of the radiation exposure spectrum. In this scenario and with this guideline, CT and ultrasound both were rated as "usually appropriate" yet have dramatically different radiation exposure risks.

Our results suggest that point-of-care access to RADS and imaging guidelines influences clinical decision making. There was a statistically significant difference in imaging modality selection when the first group received the ACR guidelines after their initial imaging choice. This effect was not noted when the second group received RADS after their initial choice.

The order in which family physicians received the information also affected their imaging modality selection. There was a statistically significant difference in imaging selection when the first group received RADS after the ACR guideline presentation. This did not occur in the second group, which received ACR guideline information after estimated radiation exposure decision support.

Our finding that ultrasound was the most frequently ordered modality across groups potentially suggests an underlying awareness of and concern for childhood radiation exposure. This also was demonstrated when both groups increased ultrasound use and decreased CT use when presented with data about estimated radiation exposure. This shift was more pronounced when such information was presented following the ACR Appropriateness Criteria guidelines presentation, likely because of the highest rating for CT in those guidelines. This result is consistent with our previous findings in adult patients. ${ }^{\text {? }}$

The ACR Appropriateness Criteria alone also seemed to influence the imaging modality selection. Both CT and ultrasound were rated as "usually appropriate," but CT had the highest ACR rating among the 7 options, and CT selection increased whenever this information was presented. Interestingly, when family physicians initially (without decision support) selected an imaging modality rated "usually not appropriate" (eg, arteriography of the kidneys or magnetic resonance imaging of the abdomen and pelvis with or without contrast) ${ }^{10}$ subsequent presentation of the ACR Appropriateness Criteria eliminated the selection of these modalities in future decisions.

We acknowledge that this study involved a simulated case. Research suggests that imaging decisions made during an actual patient encounter may be influenced by external considerations such as patient expectations ${ }^{4,6}$ and the practice of "defensive" medicine, ${ }^{5,6}$ potentially limiting the generalizability of our findings. Also, our data were collected from a cohort of predominantly military physicians practicing within the MHS. This limitation is mitigated by studies suggesting similarities between physician behavior and patients in the MHS versus those in large civilian health care systems. ${ }^{9}$ While a CT may be obtained following a negative ultrasound, the opposite is rarely true; this is an additional limitation that may have influenced image ordering after decision support.

In this pediatric clinical scenario with 2 "usually appropriate" medical imaging options available, providing clinical decision support led to the selec- 
tion of a guideline-recommended modality with lower estimated radiation exposure. This information could help inform safe, accurate, and clinically useful decision support algorithms in future electronic medical record systems.

\section{References}

1. Shah KH, Slovis BH, Runde D, Godbout B, Newman DH, Lee J. Radiation exposure among patients with the highest CT scan utilization in the emergency department. Emerg Radiol 2013;20:485-91.

2. Miglioretti DL, Johnson E, Williams A, et al. The use of computed tomography in pediatrics and the associated radiation exposure and estimated cancer risk. JAMA Pediatr 2013;167:700-7.

3. Morgan WF, Bair WJ. Issues in low dose radiation biology: the controversy continues. A perspective. Radiat Res 2013;179:501-10.

4. Armao D, Semelka RC, Elias J. Radiology's ethical responsibility for healthcare reform: tempering the overutilization of medical imaging and trimming down a heavyweight. J Magn Reson Imaging 2012; 35:512-7.

5. Rosenthal DI, Weilburg JB, Schultz T, et al. Radiology order entry with decision support: initial clinical experiences. J Am Coll Radiol 2006;3:799-806.
6. Lehnert BE, Bree RL. Analysis of appropriateness of outpatient CT and MRI referred from primary care clinics at an academic medical center: how critical is the need for improved decision support. J Am Coll Radiol 2010;7:192-7.

7. Lin FY, Rosenbaum LR, Gebow D, et al. Cardiologists concordance with the American College of Cardiology appropriate use criteria for cardiac testing in patients with coronary artery disease. Am J Cardiol 2012;110:337-44.

8. DeVries A, Young PC, Wall E, et al. CT scan utilization patterns in pediatric patients with recurrent headaches. Pediatrics 2013;132(1):e1-8.

9. Gimbel RW, Fontelo P, Stephens MB, et al. Radiation exposure and cost influence physician medical image decision making: a randomized controlled trial. Med Care 2013;51:628-32.

10. Dillman J, Coley B, Karmazyn B, et al. ACR appropriateness criteria, hematuria - child [online publication]. Reston, VA: American College of Radiology; 2012. Available from: http://www.guideline.gov/ content.aspx?id=43874. Accessed March 17, 2015.

11. Goske MJ, Applegate KE, Bulas D, et al. Image gently 5 years later: what goals remain to be accomplished in radiation protection for children? AJR Am J Roentgenol 2012;199:477-9. 


\section{Appendix 1}

Screenshots Each Participant Viewed During the Study

Clinical Scenario

\begin{tabular}{|lll}
\hline Patient Y 001-23-4567 Family Medicine Clinic & 20 \\
\hline
\end{tabular}

HPI: Patient is a 6-year-old girl who presents with new onset diffuse intermittent mild-to-sharp nonradiating abdominal pain of 2 days duration. Mom observed red urine and possibly increased urinary frequency for the past 2 days. When she is asked, patient states that she hurts "everywhere" and points to her abdomen. Mother denies h/o physical or sexual trauma. Patient had been in good health prior to the current complaint, she is not on any medications, no h/o recent travel, and there has been no change in bowel habits.

Family History: No significant PFH.

Medications: None.

Allergies: NKDA.

Physical exam: Healthy-appearing Caucasian afebrile girl at 50\% for height and weight by age. No focal neurological deficits, including grossly normal hearing. Normal heart rate, blood pressure, and respiratory rate. Lungs are clear, heart RRR no murmurs. Abdominal and back exam are significant only for mild generalized discomfort with no tenderness to palpation and no CVAT. There is no edema, rashes, bruising, and bleeding. Kidney's not appreciated. There is no joint pain.

Laboratory studies: CBC; normal hemoglobin/hematocrit, WBC 14.0. Normal Basic Metabolic Profile (BMP) and normal BUN/creatinine.

UA: Tea-colored urine. Dipstick does not demonstrate bacteria and leukocyte esterase and nitrites are negative.

Based on your initial differential, you decide to order imaging.

Please click on the arrow to order your imaging test for your patient.

Initial imaging choices (without decision support)

\begin{tabular}{|lll}
\hline Patient Y & $001-23-4567$ & Family Medicine Clinic \\
\hline
\end{tabular}

Which one imaging test do you order for your patient?

Select your single best choice from the seven imaging tests below.

\begin{tabular}{|ll|}
\hline Order & Imaging tests \\
\hline$\square$ & Arteriography kidneys \\
\hline$\square$ & CT abdomen and pelvis without contrast \\
\hline$\square$ & X-ray voiding cystourethrography \\
\hline$\square$ & X-ray abdomen and pelvis \\
\hline$\square$ & X-ray intravenous urography \\
\hline$\square$ & US kidneys and bladder \\
\hline$\square$ & MRI abdomen and pelvis without or with contrast \\
\hline
\end{tabular}




\begin{tabular}{|lll}
\hline Patient Y & 001-23-4567 Family Medicine Clinic \\
\hline
\end{tabular}

The American College of Radiology has published appropriateness criteria for imaging for pediatric nontraumatic painful hematuria.

Their appropriateness ratings are:

Usually appropriate $=7-9$

May be appropriate $=4-6$

Usually not appropriate $=1-3$

Knowing this, which one imaging test do you order for your patient? Select your single best choice from the seven imaging tests below.

\begin{tabular}{|llc|}
\hline Order & Imaging tests & $\begin{array}{c}\text { ACR appropriateness } \\
\text { rating }\end{array}$ \\
\hline$\square$ & CT abdomen and pelvis without contrast & 8 \\
\hline$\square$ & US kidneys and bladder & 7 \\
\hline$\square$ & X-ray abdomen and pelvis & 6 \\
\hline$\square$ & X-ray intravenous urography & 2 \\
\hline$\square$ & X-ray voiding cystourethrography & 2 \\
\hline$\square$ & MRI abdomen and pelvis with or without & 2 \\
\hline & contrast & 2 \\
\hline
\end{tabular}

\begin{tabular}{|lll}
\hline Patient Y & $001-23-4567$ & Family Medicine Clinic \\
\hline
\end{tabular}

The American College of Radiology suggests that the following imaging tests can be considered in this clinical condition, but differ with respect to their estimated patient radiation exposure. Population-based epidemiological studies suggest an increased cancer risk when a patient's cumulative lifetime radiation exposure exceeds $100 \mathrm{mSv}$. Radiation exposure early in life further increases the cancer risk. Knowing this, which one imaging test do you order for your patient?

Select your single best choice from the imaging tests below.

\begin{tabular}{|llc|}
\hline Order & Imaging tests & $\begin{array}{c}\text { Estimated relative } \\
\text { radiation level }\end{array}$ \\
\hline$\square$ & CT abdomen and pelvis without contrast & $3-10 \mathrm{mSv}$ \\
\hline$\square$ & Arteriography kidneys & $3-10 \mathrm{mSv}$ \\
\hline$\square$ & X-ray abdomen and pelvis & $0.3-3 \mathrm{mSv}$ \\
\hline$\square$ & X-ray intravenous urography & $0.3-3 \mathrm{mSv}$ \\
\hline$\square$ & X-ray voiding cystourethrography & $0.03-0.3 \mathrm{mSv}$ \\
\hline$\square$ & $\begin{array}{l}\text { MRI abdomen and pelvis with or without } \\
\text { contrast }\end{array}$ & 0 \\
\hline$\square$ & US kidneys and bladder & 0 \\
\hline
\end{tabular}


Appendix 2

Participant Demographics

\begin{tabular}{lccc}
\hline & $\begin{array}{c}\text { ACR-RADS } \\
(\mathrm{n}=57)\end{array}$ & $\begin{array}{c}\text { RADS-ACR } \\
(\mathrm{n}=58)\end{array}$ & $\begin{array}{c}\text { Both Groups } \\
(\mathrm{n}=115)\end{array}$ \\
\hline Attending physician & $46(80.7 \%)$ & $46(79.3 \%)$ & $92(80.0 \%)$ \\
Trainee & $11(19.3 \%)$ & $12(20.7 \%)$ & $23(20.0 \%)$ \\
Civilian & $8(14.0 \%)$ & $10(17.2 \%)$ & $18(15.7 \%)$ \\
Uniformed & $49(85.6 \%)$ & $48(82.8 \%)$ & $97(84.3 \%)$ \\
Sex & & & $28(24.3 \%)$ \\
$\quad$ Female & $13(22.8 \%)$ & $15(25.9 \%)$ & $87(75.7 \%)$ \\
$\quad$ Male & $44(77.2 \%)$ & $43(74.1 \%)$ & \\
Age (years) & & & $23(20.0 \%)$ \\
$\quad \leq 30$ & $10(17.5 \%)$ & $13(22.4 \%)$ & $47(40.9 \%)$ \\
$31-40$ & $24(42.1 \%)$ & $23(39.7 \%)$ & $35(30.4 \%)$ \\
$41-50$ & $21(36.9 \%)$ & $14(24.1 \%)$ & $10(8.7 \%)$ \\
$>50$ & $2(3.5 \%)$ & $8(13.8 \%)$ & $53(46.1 \%)$ \\
Experience (years) & & & $27(23.5 \%)$ \\
$\quad 5$ & $28(49.1 \%)$ & $25(43.1 \%)$ & $35(30.4 \%)$ \\
$5-10$ & $14(24.6 \%)$ & $13(22.4 \%)$ & \\
$>10$ & $15(26.3 \%)$ & $20(34.5 \%)$ & \\
\hline
\end{tabular}

Groups were statistically compared using the $\chi^{2}$ test for homogeneity.

ACR-RADS, American College of Radiology Appropriateness Criteria then estimated radiation exposure information; RADS-ACR, estimated radiation exposure information then American College of Radiology Appropriateness Criteria. 